Case Report

\title{
Eosinophilic Granulomatosis with Polyangiitis Presenting as Acute Polyneuropathy Mimicking Guillain-Barre Syndrome
}

\author{
Carlos R. Camara-Lemarroy, ${ }^{1}$ Adrian Infante-Valenzuela, ${ }^{1}$ \\ Hector J. Villareal-Montemayor, ${ }^{1}$ Carlos A. Soto-Rincon, ${ }^{2}$ \\ Javier A. Davila-Olalde, ${ }^{2}$ and Hector J. Villareal-Velazquez ${ }^{1}$ \\ ${ }^{1}$ Servicio de Neurologia, Hospital Universitario “Dr. José E. González” y Facultad de Medicina, Universidad Autónoma de Nuevo León, \\ Madero y Gonzalitos, S/N, 64460 Monterrey, NL, Mexico \\ ${ }^{2}$ Departamento de Medicina Interna, Hospital Universitario “Dr. José E. González” y Facultad de Medicina, \\ Universidad Autónoma de Nuevo León, Madero y Gonzalitos, S/N, 64460 Monterrey, NL, Mexico
}

Correspondence should be addressed to Carlos R. Camara-Lemarroy; crcamara83@hotmail.com

Received 26 May 2015; Revised 13 June 2015; Accepted 15 June 2015

Academic Editor: Peter Berlit

Copyright (C) 2015 Carlos R. Camara-Lemarroy et al. This is an open access article distributed under the Creative Commons Attribution License, which permits unrestricted use, distribution, and reproduction in any medium, provided the original work is properly cited.

Eosinophilic granulomatosis with polyangiitis (EGPA) is a small-vessel vasculitis associated with antineutrophil cytoplasmic antibodies (ANCAs) which commonly affects the peripheral nervous system. A 38-year-old female with a history of asthma presented with a 2-week history of bilateral lower extremity paresthesias that progressed to symmetric ascending paralysis. Nerve conduction studies could not rule out Guillain-Barre syndrome (GBS) and plasmapheresis was considered. Her blood work revealed marked eosinophilia ( $>50 \%$ ), she had purpuric lesions in her legs, and a head magnetic resonance image showed evidence of pansinusitis. Coupled with a history of asthma we suspected EGPA-associated neuropathy and started steroid treatment. The patient showed rapid and significant improvement. ANCAs were later reported positive. ANCA-associated vasculitides present most often as mononeuritis multiplex, but they can mimic GBS and should always be considered in the differential diagnosis, since the treatment strategies for these conditions are radically different.

\section{Introduction}

Churg-Strauss syndrome, a small-vessel vasculitis associated with antineutrophil cytoplasmic antibodies (ANCAs), was first described in 1951 by Churg and Strauss as a rare disease characterized by disseminated necrotizing vasculitis occurring among patients with asthma and eosinophilia. It is now termed eosinophilic granulomatosis with polyangiitis (EGPA). The diagnosis of EGPA is based on ACR 1990 criteria (4 or more of the following: asthma, eosinophilia $>10 \%$, neuropathy, nonfixed pulmonary infiltrates, paranasal sinus abnormality, and extravascular eosinophils) [1]. During the vasculitic phase, besides renal and pulmonary disease, central and peripheral nervous system involvement may occur, with polyneuropathy, radiculopathy, and mononeuritis multiplex being common presentations [2]. GuillainBarre syndrome (GBS) is a clinical syndrome of an acute inflammatory polyneuropathy, characterized by mild sensory loss, ascending weakness, and hypo- or areflexia, progressing to a nadir over up to four weeks. Cerebrospinal fluid evaluation demonstrates albuminocytologic dissociation in $90 \%$ of cases. GBS encompasses a number of subtypes with evidence of different clinical, neurophysiological, and immunological mechanisms [3]. In two-thirds there is history of an infection, usually of the upper respiratory system or gastroenteritis. We present a case of EGPA presenting as GBS syndrome. Both GBS and EGPA are rare diseases (approximately 1/100,000), and differentiating between GBS and EGPA-associated vasculitic polyneuropathy is important, considering the different management strategies.

\section{Case Presentation}

Our patient was a 38-year-old female with an 18-year history of asthma. Two weeks before her admission to the emergency 
TABLE 1: Characteristics of patients with EGP presenting as GBS.

\begin{tabular}{|c|c|c|c|c|c|c|c|}
\hline Reference & Age (sex) & Clinical manifestations & Laboratory findings & NCS & Other & Treatment & Outcome \\
\hline [7] & $58 \mathrm{M}$ & $\begin{array}{l}\text { Symmetric weakness, } \\
\text { hyporeflexia, and asthma }\end{array}$ & $\begin{array}{l}\text { Eosinophilia, elevated } \\
\text { ERS, and p-ANCA+ }\end{array}$ & $\begin{array}{l}\text { Mixed demyelinating } \\
\text { polyneuropathy and } \\
\text { multifocal absent } \\
\text { F-waves }\end{array}$ & $\begin{array}{l}\text { Lung } \\
\text { infiltrates }\end{array}$ & $\begin{array}{l}\mathrm{P}, \mathrm{CyC} \\
\text { and } \mathrm{S}\end{array}$ & Expired \\
\hline [8] & $57 \mathrm{M}$ & $\begin{array}{l}\text { Symmetric weakness } \\
\text { and hyporeflexia }\end{array}$ & $\begin{array}{l}\text { p-ANCA+ and } \\
\text { elevated ERS }\end{array}$ & $\begin{array}{l}\text { Demyelinating } \\
\text { polyneuropathy and } \\
\text { multifocal absent } \\
\text { F-waves }\end{array}$ & Nephritis & S & Improved \\
\hline [9] & $51 \mathrm{~F}$ & $\begin{array}{l}\text { Symmetric weakness, } \\
\text { hyporeflexia, asthma, } \\
\text { and nasal polyposis }\end{array}$ & $\begin{array}{l}\text { Eosinophilia, elevated } \\
\text { CRP, and ANCA- }\end{array}$ & $\begin{array}{l}\text { Motor asymmetric } \\
\text { axonal polyneuropathy } \\
\text { and multifocal absent } \\
\text { F-waves }\end{array}$ & & IvIG and S & Improved \\
\hline [10] & $74 \mathrm{M}$ & $\begin{array}{l}\text { Symmetric weakness, } \\
\text { hyporeflexia, and asthma }\end{array}$ & Eosinophilia & $\begin{array}{l}\text { Mixed demyelinating } \\
\text { polyneuropathy }\end{array}$ & & $\mathrm{S}$ and $\mathrm{CyC}$ & Improved \\
\hline$[11]$ & $64 \mathrm{~F}$ & $\begin{array}{l}\text { Asymmetric weakness, } \\
\text { hyporeflexia, asthma, } \\
\text { diplopia, and sinusitis }\end{array}$ & $\begin{array}{l}\text { Elevated ESR, } \\
\text { eosinophilia, and } \\
\text { p-ANCA+ }\end{array}$ & $\begin{array}{l}\text { Motor axonal and } \\
\text { demyelinating } \\
\text { polyneuropathy and } \\
\text { multifocal absent } \\
\text { F-waves }\end{array}$ & $\begin{array}{l}\text { Multiorgan } \\
\text { disease }\end{array}$ & $\begin{array}{l}\text { IvIG, CyC, } \\
\text { and S }\end{array}$ & Expired \\
\hline Present case & $36 \mathrm{~F}$ & $\begin{array}{l}\text { Symmetric weakness, } \\
\text { hyporeflexia, asthma, } \\
\text { purpura, and } \\
\text { pansinusitis }\end{array}$ & $\begin{array}{l}\text { Elevated ESR, } \\
\text { eosinophilia, and } \\
\text { p-ANCA+ }\end{array}$ & $\begin{array}{l}\text { Mixed axonal } \\
\text { asymmetric } \\
\text { polyneuropathy }\end{array}$ & & $\mathrm{S}$ and $\mathrm{CyC}$ & Improved \\
\hline
\end{tabular}

NCS: nerve conduction studies; ESR: erythrocyte sedimentation rate; CRP: C-reactive protein; IvIG: intravenous immunoglobulin; CyC: cyclophosphamide; P: plasmapheresis; S: steroids.

department, she developed distal bilateral lower limb paresthesias that rapidly progressed to weakness that prevented her from standing from a chair or walking. On examination the patient was alert and cooperative. She had lower limb weakness (2/5 in both distal and proximal segments, bilaterally), hyporeflexia, and hypoesthesia. She had distal upper limb paresthesias, but strength and reflexes were normal. She had purpuric lesions in the anterior portion of both lower limbs. Oxygen saturation was normal and she did not complain of dyspnea. She had no meningeal signs or fever. Her chest Xray was normal and the only relevant findings on her routine blood work-up were a marked eosinophilia (13,200, 53\%, normal range $0-7 \%$ ) and an elevated erythrocyte sedimentation rate $(49 \mathrm{~mm} / \mathrm{h}$ : normal range $0-20)$. Renal function and urine tests were normal. A head MRI showed pansinusitis. Cerebrospinal fluid analysis showed 10 leucocytes and normal glucose and protein. Nerve conduction studies revealed bilateral peroneal, tibial, and sural conduction blocks, with absent F-waves, as well as a left median nerve conduction block. The rest of upper extremity nerves were unaffected. Considering the history of asthma and eosinophilia, we suspected an eosinophilic vasculitic polyneuropathy and immediately started our patient on steroids (1 g methylprednisolone IV). The next day there was a dramatic improvement in the patient's strength (4/5 in both lower limbs) and c-ANCAs were reported positive $(1: 80$, normal range $<1: 20)$. We continued steroid treatment (5 days), added cyclophosphamide (1 $\mathrm{g}$ single dose), and cancelled the planned plasmapheresis. Bronchial hyperreactivity was confirmed with pulmonary function tests and a skin biopsy revealed eosinophilic infiltrates. We diagnosed our patient with EGPA-associated polyneuropathy. The patient responded well to treatment, regaining full lower limb strength. She was discharged 10 days later, without any other organ involvement or new symptoms at 3 months of follow-up.

\section{Discussion}

Peripheral neuropathy is quite common in patients with EGPA. Pathological findings of vasculitic neuropathy are characterized by axonal degeneration of nerve fibers caused by vasculitis-induced ischemia. In the largest published series of patients with EGPA, 51.4-60\% had peripheral neuropathy at presentation $[4,5]$. Mononeuritis multiplex was slightly more common than symmetric polyneuropathy, and the lower limbs were predominately affected. In contrast to lung or renal involvement, peripheral neuropathy alone is rarely life threatening but does significantly affect quality of life. Although less than $40 \%$ of patients with EGPA have positive ANCAs, this subgroup of patients presents most often with neuropathy $[2,4]$. Our patient was positive for c-ANCA, while the majority (around $80 \%$ ) of patients are p-ANCA positive, although no differences in clinical characteristics have been found among these subgroups of patients [2, 4]. ANCA positivity has also been associated with lower mortality $[2,4]$.

There are at least 6 previous cases reported in the literature where EGPA presented as GBS (Table 1). In 1996, 
Ishiura et al. reported the case of a 74-year-old man who presented with eosinophilic pneumonia and later developed GBS [6]. However, this patient did not meet criteria for EGPA. $\mathrm{Ng}$ et al. first reported a case of both clinically and electrophysiologically mimicked GBS, but it was later found to be a case of EGPA due to findings of persistent eosinophilia, positive ANCAs, and eosinophilic vasculitis in a sural nerve biopsy [7]. In 1998, Keven et al. reported the case of a patient diagnosed with GBS who later developed ANCA-positive nephrotic syndrome, suggesting that the polyneuropathy could be secondary to necrotizing vasculitis [8]. Since then, at least 3 other cases of EGPA presenting as GBS have been reported, all with acute ascending polyneuropathy and neurophysiologic studies suggestive of GBS [9-11]. Eosinophilia [10] and ANCA positivity $[9,11]$ were the factors that led to the correct diagnosis, supported in some cases by treatment failure with IV immunoglobulin $[10,11]$. All of these cases followed an aggressive course, with multiorgan involvement and death in 1 case [11], and response only after combination immunosuppressive treatment (corticosteroids and cyclophosphamide) in the other 2 $[9,10]$.

Although our patient also presented with a symmetric ascending paralysis and hyporeflexia, a history of asthma, severe eosinophilia, and skin purpuric lesions raised our suspicion of EGPA. Compared to the cases mentioned above, our patient was younger, received early treatment with steroids, and had no other organ involvement, and her course was relatively benign. EGPA and other vasculitides should always be part of the differential diagnosis of GBS, as the first line treatments may differ. While steroids are of no use (and may even be harmful) in GBS, they are the mainstay of treatment in EGPA [2]. Adding cyclophosphamide could reduce recurrence of EGPA and may be life-saving when there is multiple organ involvement. On the other hand, IV immunoglobulin and plasmapheresis may be effective in both EGPA and GBS [3].

\section{Consent}

The patient described in the case report has given their informed consent for the case report to be published.

\section{Conflict of Interests}

The authors report no conflict of interests.

\section{References}

[1] A. T. Masi, G. G. Hunder, J. T. Lie et al., "The American college of rheumatology 1990 criteria for the classification of churg-strauss syndrome (allergic granulomatosis and angiitis)," Arthritis \& Rheumatism, vol. 33, no. 8, pp. 1094-1100, 1990.

[2] A. Greco, M. I. Rizzo, A. de Virgilio et al., "Churg-Strauss syndrome," Autoimmunity Reviews, vol. 14, no. 4, pp. 341-348, 2015.

[3] J. B. Winer, "An update in guillain-barré syndrome," Autoimmune Diseases, vol. 2014, Article ID 793024, 6 pages, 2014.
[4] C. Comarmond, C. Pagnoux, M. Khellaf et al., "Eosinophilic granulomatosis with polyangiitis (Churg-Strauss): clinical characteristics and long-term followup of the 383 patients enrolled in the French Vasculitis Study Group cohort," Arthritis \& Rheumatism, vol. 65, no. 1, pp. 270-281, 2013.

[5] J. Wolf, V. Schmitt, F. Palm, A. J. Grau, and R. Bergner, "Peripheral neuropathy as initial manifestation of primary systemic vasculitides," Journal of Neurology, vol. 260, no. 4, pp. 1061-1070, 2013.

[6] Y. Ishiura, H. Tsuji, S. Takeda et al., "Acute eosinophilic pneumonia accompanied by Guillain-Barré syndrome," British Journal of Clinical Practice, vol. 50, no. 5, pp. 283-285, 1996.

[7] K. K. P. Ng, H. M. Yeung, K. T. Loo, H. M. Chan, C. K. Wong, and P. C. K. Li, "Acute fulminant neuropathy in a patient with Churg-Strauss syndrome," Postgraduate Medical Journal, vol. 73, no. 858, pp. 236-238, 1997.

[8] K. Keven, G. Nergisoglu, S. Erturk et al., "A case of GuillainBarre syndrome complicated by nephrotic syndrome and pANCA positivity," Nephron, vol. 80, no. 3, pp. 361-362, 1998.

[9] N. Riva, F. Cerri, C. Butera et al., "Churg Strauss syndrome presenting as acute neuropathy resembling Guillain Barré syndrome: case report," Journal of Neurology, vol. 255, no. 11, pp. 1843-1844, 2008.

[10] M. Djukic, H. Schmidt, C. Mazurek, F. König, S. Schweyer, and R. Nau, "A patient with Churg-Strauss syndrome presenting as Guillain-Barré syndrome," Nervenarzt, vol. 79, no. 4, pp. 457461, 2008.

[11] L. De Toni Franceschini, S. Amadio, M. Scarlato et al., "A fatal case of Churg-Strauss syndrome presenting with acute polyneuropathy mimicking Guillain-Barré syndrome," Neurological Sciences, vol. 32, no. 5, pp. 937-940, 2011. 


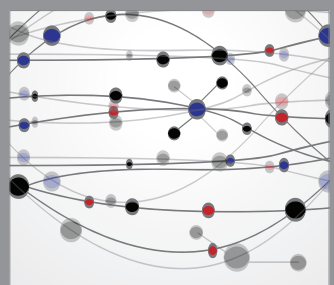

The Scientific World Journal
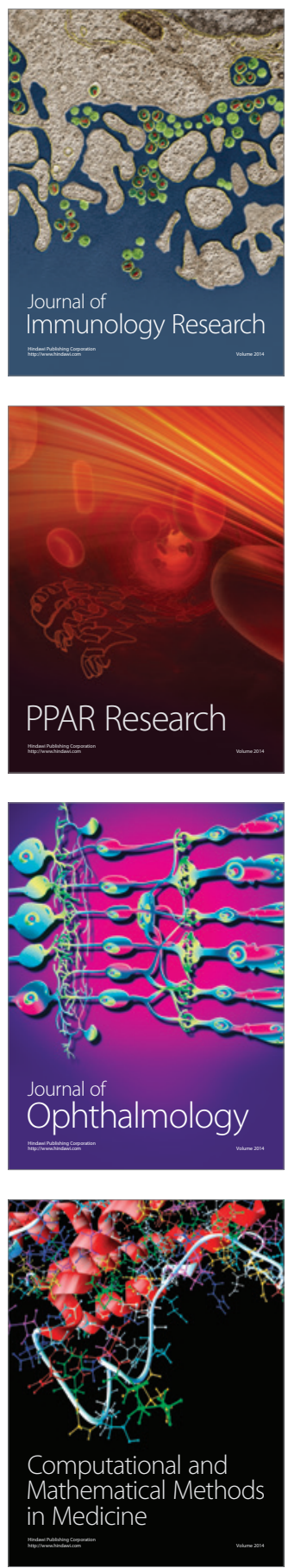

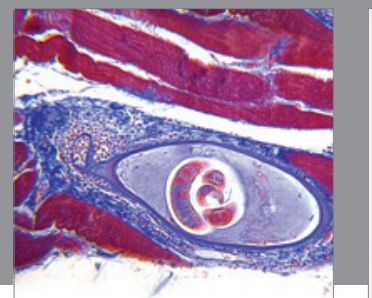

Gastroenterology

Research and Practice
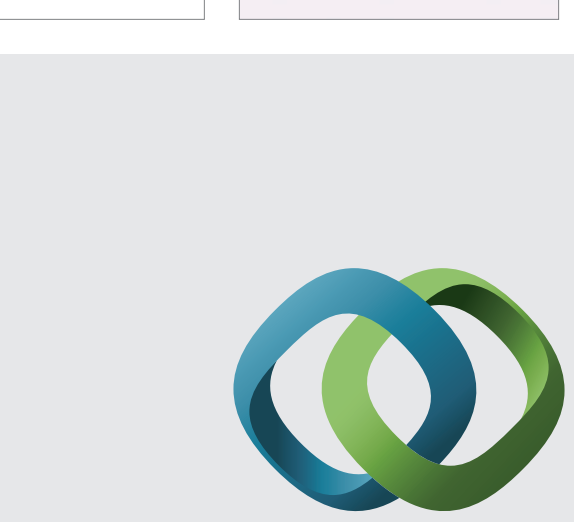

\section{Hindawi}

Submit your manuscripts at

http://www.hindawi.com
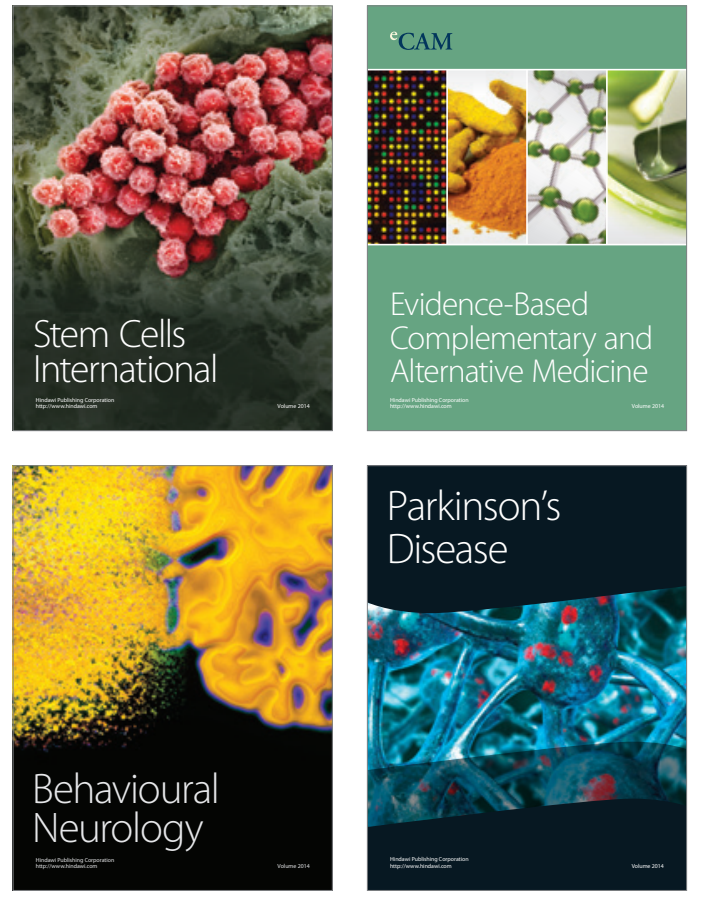
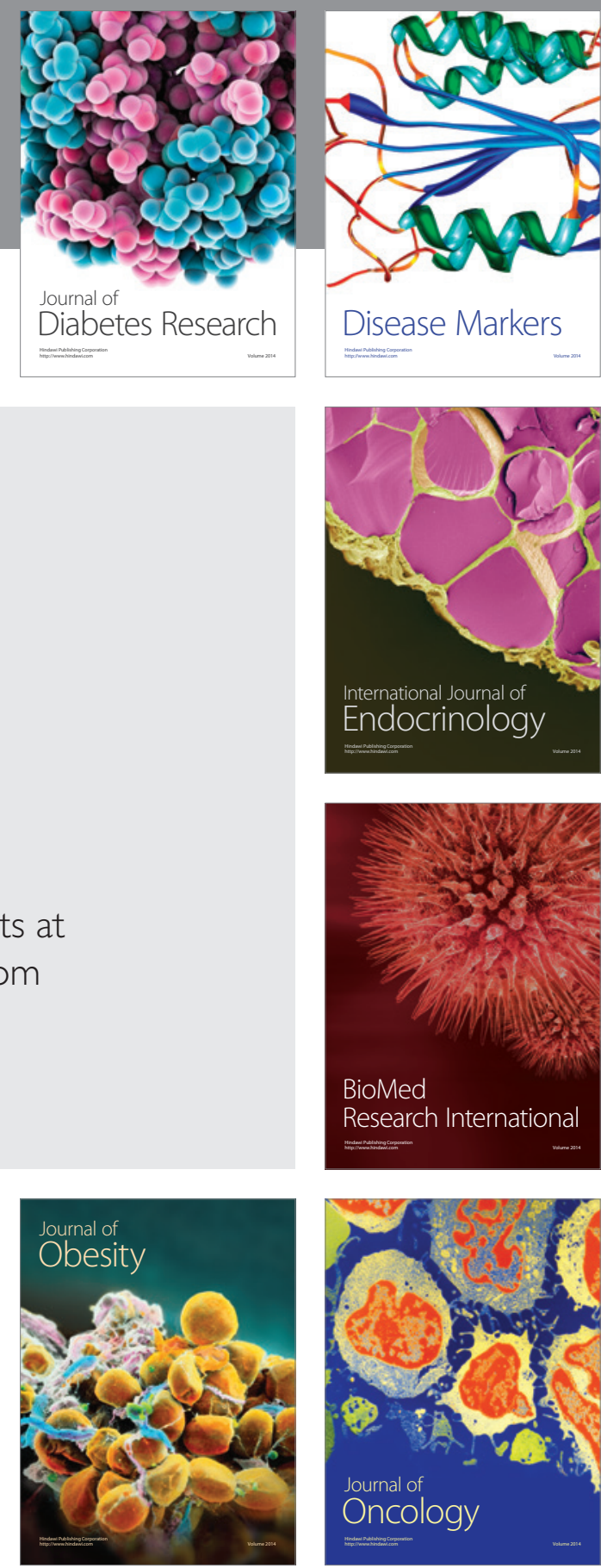

Disease Markers
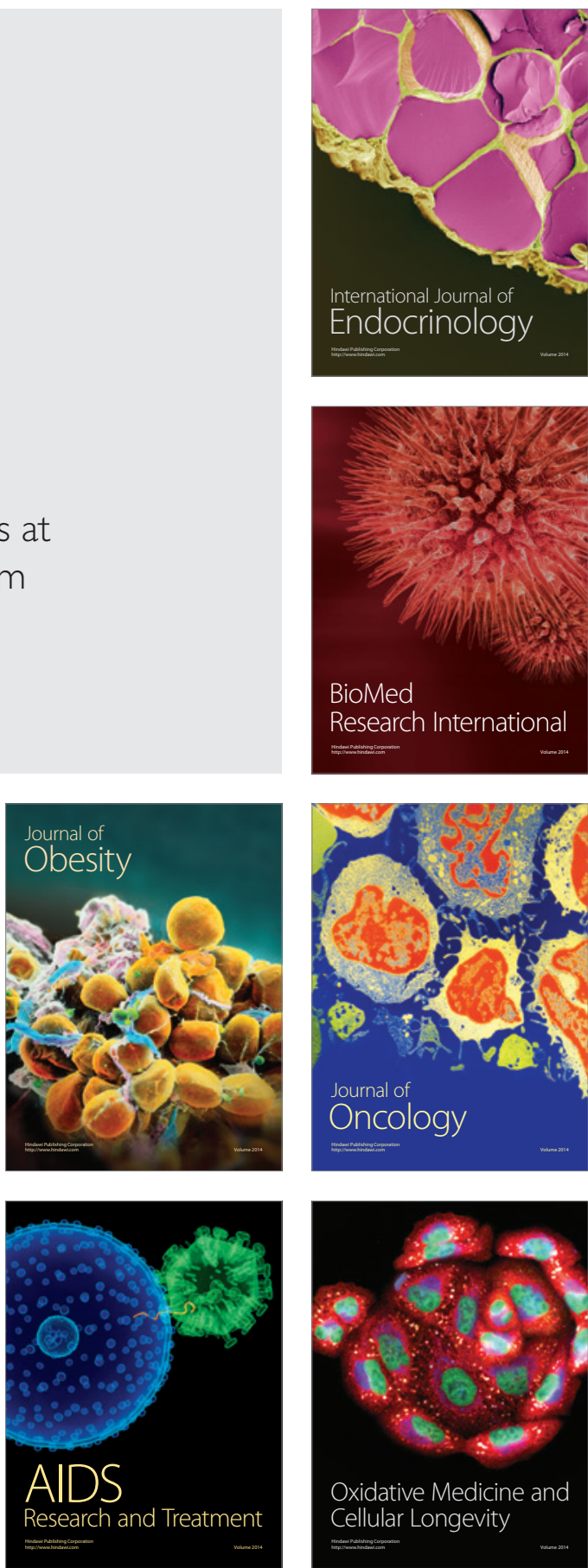